\title{
Studying Kinematics and Capacity of Tools of Organic Fertilizer Loader
}

\author{
Evgeny Evgenievich Demin ${ }^{1}$, Pavel Ivanovich Pavlov ${ }^{1}$, Rustam Rafitovich Khakimzyanov ${ }^{1}$, Victor Alekseevich \\ Mukhin', Andrey Anatolyevich Protasov ${ }^{1}$
}

${ }^{1}$ Saratov State Agrarian University, Saratov, 410012 Russia

\begin{abstract}
This article discusses the issue of theoretical background of capacity of new load handling tools of continuous loaders for organic fertilizers on the basis of kinematic analysis of their motion. Loader efficiency is estimated by a set of performances the main of which is loading capacity. The loading capacity is determined by design and kinematic parameters of tools. Theoretical determination of capacity is an important scientific task, its solution would permit to substantiate loader parameters for predetermined operation conditions. Kinematic analysis of spiral, vane, shredding screw load handling tools is performed. Capacity of shredding tools is determined as a function of design and operation parameters as well as physicochemical properties of organic fertilizers. The obtained equations take into account motion pattern of tools, kinematic and design parameters as well as physicochemical properties of manure. The capacity depends quadratically on tool diameter. Dependence on other parameters is in fact directly proportional. The influence of tool angular velocity and its forward velocity is related with trigonometric functions of rotation angles during separation and gripping of organic fertilizers.
\end{abstract}

Keywords: Continuous Loaders, Capacity, Load Handling Tool, Spiral Feeder, Vane Feeder, Shredding Screw Feeder.

\section{Introduction}

Application of fertilizers is the main source to maintain and improve fertility of agricultural lands used for cultivation of cereal and leguminous crops. Organic fertilizers can be accumulated and used in liquid, semiliquid, and solid forms [1-3]. Technology of accumulation, storage, treatment, and distribution of organic fertilizers in solid form is widely applied by cattle farms. This technology is based on certain procedures with various time and labor consumptions. One of the most labor consuming procedures is loading of the obtained fertilizers to machinery for distribution or transportation. This can be performed by batch-type or continuous loaders [3-4]. Application of continuous loaders for manure makes it possible to carry out this procedure with higher efficiency, lower power consumptions, and to obtain granulated substance and ready for further distribution [3, 4]. The main tool of continuous loader is feeder which separates and grips portions of manure from heap and then delivers them to loading conveyor. Saratov State Agrarian University developed a set of tools [5-8] making it possible to efficiently load solid organic fertilizers from heaps, manure storage, as well as on by-farm sites.

The loader efficiency is estimated by certain performances among which loading capacity is one of the most important. The capacity is determined by design and kinematic parameters of tools. Theoretical determination of the capacity is an important issue, its solution would permit to substantiate loader parameters for predetermined operation conditions.

\section{Methods}

Capacity of tools of continuous loader is related with analysis of kinematic parameters of their motion. The most important parameters which could be obtained by kinematic analysis include the surface area of lateral projection and amount of separated from the main bulk portion of organic fertilizers.

Let us consider kinematics of motions of tools proposed for various tools' loading conditions of organic fertilizers: spiral, vane, and shredding screw feeders of continuous loader.

The point path on cutting blade of spiral feeder (Fig. 1, a) is described as follows:

$$
\left.\begin{array}{l}
X=R \cos (\omega t)+v_{F} t \\
Y=R \sin (\omega t)
\end{array}\right\},
$$

where $X$ and $Y$ are the coordinates of tool point in plane vertical coordinates; $R$ is the rotation radius of a certain point $\mathrm{A}$ on $(\mathrm{m}) ; \omega$ is the angular velocity of tool point rotation $(\mathrm{rad} / \mathrm{s}) ; v_{F}$ is the forward motion velocity $(\mathrm{m} / \mathrm{s}) ; t$ is the time after the motion start (s).
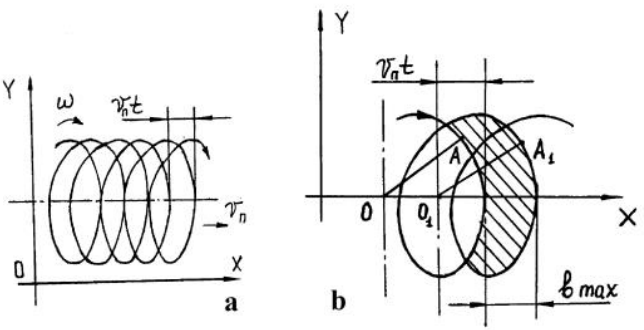

Fig. 1: Schematic view of kinematic parameters of spiral feeder: a) path of a tool point; b) surface area of lateral projection of detachable part.

Each point on cutting edge of rotor of vane feeder moves in spatial system of coordinates (Fig. 2, a), hence, the system is comprised of three parametric equations: 


$$
\left.\begin{array}{l}
X=X_{0}+v_{\Pi} t+\cos \alpha R \cos \left(\varphi_{0}+\omega t\right) \\
Y=Y_{0}+R \sin \left(\varphi_{0}+\omega t\right) \\
Z=Z_{0}+\sin \alpha R \cos \left(\varphi_{0}+\omega t\right)
\end{array}\right\},
$$

where $\alpha$ is the inclination angle of motion path to horizontal plane; $\varphi_{0}$ is the initial angle of vane position; $X_{0}, Y_{0}, Z_{0}$ are the initial point coordinates.

Motion of a point of shredding drum of shredding screw feeder (Fig. 3, a) is characterized by the fact that the relative and transportation motions are rotational. The set of parametric equations describing this motion is as follows:

$$
\left.\begin{array}{l}
x=l_{c} \cos \theta+r_{s h} \cos \phi \\
y=l_{c} \sin \theta+r_{s h} \sin \phi
\end{array}\right\},
$$

where $\theta=\theta_{0}+\omega_{c} t$ is the angle of arm turn; $\phi=\phi_{0}+\omega_{s h} t$ is the angle of shredder turn; $l_{c}$ is the arm length, $\mathrm{m} ; r_{s h}$ is the radius of shredding drum, $\mathrm{m} ; \omega_{s h}$ is the angular velocity of shredding drum, $\mathrm{rad} / \mathrm{s} ; \omega_{c}$ is the arm angular velocity, $\mathrm{rad} / \mathrm{s}$.

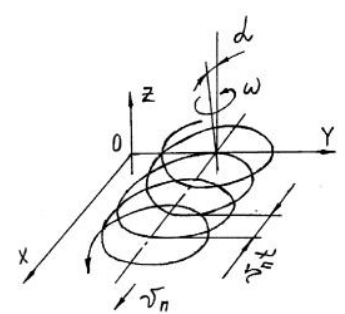

a

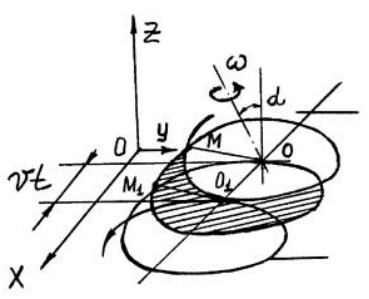

b
Fig. 2: Schematic view of kinematic parameters of vane feeder: a) path of a tool point; b) surface area of lateral projection of detachable part.
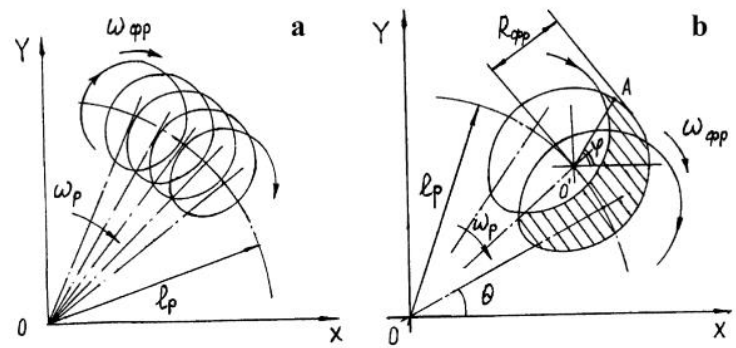

Fig. 3: Schematic view of kinematic parameters of shredding screw feeder: a) path of a tool point; b) surface area of lateral projection of chipping.

The surface area of lateral projection separated from the main bulk portion of organic fertilizers is the area between two neighboring turns of motion path (Fig. 1, b). This area is defined as the integral [9]:

$A= \pm \int_{0}^{T} Y(t) \dot{X}(t) d t$

provided that:

$$
\left\{\begin{array}{l}
x=x(t) \quad 0 \leq t \leq T \\
y=y(t)
\end{array}\right.
$$

The sign " + " is selected when the curve is oriented positively, that is, while going around the curve the region remains at the left. The sign "-" is used in another case [10]; $\dot{X}$ is the first derivative of the coordinate $X$ with time.

For spiral feeder the area of lateral projection of the separated portion (Fig. 1, b) with consideration for Eqs. (1) and (4) will be as follows:

$$
A_{1}=-\int_{0}^{T}\left(-R \omega \sin (\omega t)+v_{F}\right) R \sin (\omega t) d t=-\int_{0}^{T}\left(-R^{2} \omega \sin ^{2}(\omega t)+v_{F} R \sin (\omega t)\right) d t
$$

where $\dot{X}(t)=\left(-R \omega \sin (\omega t)+v_{F}\right)$ is the first derivative of the coordinate $X$ with time.

Solving Eq. (5) we obtain as follows:

$\mathrm{A}_{1}=R^{2} \frac{\omega t}{2}-\frac{R^{2}}{4} \sin (2 \omega t)+\frac{v_{F} R}{\omega} \cos (\omega t)$,

For a vane feeder the area of lateral projection is the dashed area in Fig. 2, b. With consideration for Eq. (2):

$A_{2}= \pm \int_{t_{1}}^{t_{2}} y(t) \dot{x}(t) d t= \pm \int_{t_{1}}^{t_{2}} R \sin \left(\phi_{0}+\omega t\right) \cdot\left[v_{F}-\right.$

$\left.\cos \alpha \cdot R \cdot \omega \cdot \sin \left(\varphi_{0}+\omega t\right)\right] d t$

where $\dot{x}(t)=v_{F}-\cos \alpha \cdot R \cdot \omega \cdot \sin \left(\phi_{0}+\omega t\right)$ is the first derivative of the coordinate $X$ with time, $t_{1}, t_{2}$ is the start and end times, respectively.

Solving Eq. (7) we obtain the equation for determination of its area:

$A_{2}=\frac{v_{F} R}{\omega} \cos (\omega t)+\frac{R^{2} \omega \cos \alpha}{2} t-\frac{R^{2} \cos \alpha}{4} \sin (2(\omega t))$,

For a shredding screw feeder with consideration for eq. (3) the first derivative of the coordinate $X$ with time will be as follows:

$x^{\prime}(t)=-l_{c} \omega_{c} \sin \theta-r_{s h} \omega_{s h} \sin \phi$,

Then,

$$
\begin{aligned}
& y(t) x^{\prime}(t)=-\left(l_{c} \omega_{c} \sin \theta+r_{s h} \omega_{s h} \sin \phi\right)\left(l_{c} \sin \theta+r_{s h} \sin \phi\right)= \\
= & -\left[l_{c}^{2} \omega_{c} \sin ^{2} \theta+r_{s h}^{2} \omega_{s h} \sin ^{2} \phi+l_{c} r_{s h}\left(\omega_{c}+\omega_{s h}\right) \sin \theta \sin \phi\right]
\end{aligned}
$$

Converting Eq. (9) and substituting it into Eq. (4), and solving this integral we obtain the area of lateral projection of fertilizer portion separated by shredding drum, $\mathrm{m}^{2}$ :

$$
\begin{aligned}
A_{3} & =\left[\left(l_{c}^{2} \omega_{c}+r_{s h}^{2} \omega_{s h}\right) / 2\right] t-\left(l_{c}^{2} \sin (2 \theta)\right) / 4-\left(r_{s h}^{2} \sin (2 \phi)\right) / 4+ \\
& +\left[l_{c} r_{s h}\left(\omega_{c}+\omega_{s h}\right) \sin (\theta-\phi)\right] /\left[2\left(\omega_{c}-\omega_{s h}\right)\right]-l_{c} r_{s h} \sin (\theta+\phi) / 2
\end{aligned}
$$

On the basis of equations for area of lateral projection it is possible to determine the amount of organic fertilizers spirited from the heap by the proposed loader tools.

For a spiral feeder the amount of organic fertilizers separated from the main bulk is as follows:

$V_{1}=\left[R^{2} \frac{\omega t}{2}-\frac{R^{2}}{4} \sin (2 \omega t)+\frac{v_{n} R}{\omega} \cos (\omega t)\right] k_{0} b$,

where $k_{0}$ is the coefficient of filling; $b$ is the width of separated portion, $\mathrm{m}$.

For a vane feeder the manure volume, $\mathrm{m}^{3}$, separated by one vane is:

$V_{2}=\left[\frac{v_{n} R}{\omega} \cos (\omega t)+\frac{R^{2} \omega \cos \alpha}{2}-\frac{R^{2} \cos \alpha}{4} \sin (2 \omega t)\right] k_{0} H$,

where $H$ is the heap height gripped by one vane.

For a shredding screw feeder the separated volume, $\mathrm{m}^{3}$, is:

$$
V_{G}=A_{G} b_{g}=b_{G}\left[\left[\left(l_{C}^{2} \omega_{C}+r_{s h}^{2} \omega_{s h}\right) / 2\right] t-\left(l_{c}^{2} \sin (2 \theta)\right) / 4-\right.
$$


$-\left(r_{s h}^{2} \sin (2 \phi)\right) / 4+\left[l_{c} r_{s h}\left(\omega_{c}+\omega_{s h}\right) \sin (\theta-\phi)\right] /\left[2\left(\omega_{c}-\omega_{s h}\right)\right]-$

$\left.-l_{c} r_{s h} \sin (\theta+\phi) / 2\right] k_{0}$,

where $b_{G}$ is the width of organic fertilizers separated by shredding drum; $t$ is the time of drum motion in manure heap.

The performed kinematic and mathematical analysis made it possible to obtain equations for determination of capacity of the proposed tools.

\section{Results}

The capacity, weight of organic fertilizers [11-13], separated and gripped by loader tools per unit time, is, $\mathrm{kg} / \mathrm{s}$ :

$Q=\frac{m}{t}=\frac{\rho V}{t}$,

where $m$ is the weight of separated and gripped organic fertilizers, $\mathrm{kg} ; t$ is the time of separation and gripping of the weight $m, \mathrm{~s} ; \rho$ is the fertilizer density, $\mathrm{kg} / \mathrm{m}^{3} ; V$ is the volume of separated portion, $\mathrm{m}^{3}$.

The capacity, $\mathrm{kg} / \mathrm{s}$, of spiral tool with consideration for number of blades $z_{t}$ participating simultaneously in manure separation from heap is as follows:

$Q=\left(R_{c}^{2} \frac{\omega t}{2}-\frac{R_{c}^{2}}{4} \sin (2 \omega t)+\frac{v_{F} R_{c}}{\omega} \cos (\omega t)\right) \cdot \frac{k_{0} b \rho z_{t} \omega}{2 \pi}$,

where $t=\frac{2 \pi}{\omega}$ is the time of separation and gripping by one blade, $R_{c}$ is the radius along which the cutting blades are installed. The capacity of vane feeder is, $\mathrm{kg} / \mathrm{s}$ :

$Q_{V}=\frac{\rho z_{t} \omega k_{0} H}{2 \pi}\left[\frac{v_{F} R_{c}}{\omega} \cos (\omega t)+\frac{R_{c}^{2} \omega \cos \alpha}{2} t-\right.$,

$\left.-\frac{R_{c}^{2} \cos \alpha}{4} \sin (2 \omega t)\right]$

where $Z_{t}$ is the number of feeder vanes in load bulk at the time $t$;

$R_{c}$ is the rotor radius; $\boldsymbol{\omega}$ is the angular velocity of vane rotation. Taking into account the number of separating elements in load bulk $Z_{t}$, the capacity of shredding screw feeder is, $\mathrm{kg} / \mathrm{s}$ :

$Q_{s h}=\frac{\rho b_{v} z_{t} \omega_{s h} k_{0}}{2}\left[\left[\left(l_{c}^{2} \omega_{c}+R_{s h}^{2} \omega_{s h}\right) / 2\right] t-\left(l_{c}^{2} \sin (2 \theta)\right) / 4-\right.$

$-\left(R_{s h}^{2} \sin (2 \phi)\right) / 4+\left[l_{c} R_{s h}\left(\omega_{c}+\omega_{s h}\right) \sin (\theta-\phi)\right] /\left[2\left(\omega_{c}-\omega_{s h}\right)\right]-$ $\left.-l_{c} R_{s h} \sin (\theta+\phi) / 2\right]$

\section{Conclusion}

Therefore, mathematical equations have been obtained for determination of capacity of shredding tools of continuous loaders for organic fertilizers. The equations take into account motion pattern of tools, kinematic and design parameters, as well as physicochemical properties of manure. The capacity depends quadratically on tool diameter. Dependence on other parameters is in fact directly proportional. The influence of operation parameters is more complicated. The influence of tool angular velocity and its forward velocity is related with trigonometric functions of rotation angles during separation and gripping of organic fertilizers.

The obtained equations make it possible to determine capacity on the basis of known design and operation parameters, or to solve the inverse problem: determination of tool parameters on the basis of known capacity.

\section{References}

[1] Marchenko NM (1991), Tekhnologiya i tekhnicheskie sredstva dlya vneseniya organicheskikh udobrenii [Technology and tools for fertilizer treatment]. Moscow: Rosagropromizdat.

[2] Vasil'ev VA, Filippova NV (1988), Spravochnik po organicheskim udobreniyam [Organic fertilizers. Guidebook]. Moscow: Rosagropromizdat.

[3] Pavlov PI (2002), R\&D solutions of resource saving upon operation continuous manure loader: Doctoral thesis: 05.20.01. Saratov.

[4] Pavlov PI, Dzyuban IL (2014), Rezul'taty issledovanii proizvoditel'nosti pogruzchika-smesitelya organomineral'nogo komposta [Studying capacity of loader-mixer of organic mineral compost]. Vestnik Saratovskogo gosagrouniversiteta im. N.I. Vavilova, 7, 35-37.

[5] Kononov BV, Volkov YuI, Pavlov PI (1992), Spiral feeder, Authors certificate № 1740292. Byull, 22.

[6] Pavlov PI, Khitrova NV (1997), Shredding spiral feeder, RF patent № 2083463, Byull, 19.

[7] Dubinin VF, Pavlov PI (1997), Vane feeder, RF patent № 2071234 Byull, 1.

[8] Pavlov PI, Dyomin EE, Khakimzyanov RR (2006), Pitatel' frezeruyushchego tipa dlya pogruzki organicheskikh udobrenii [Shredding feeder for loading of organic fertilizers]. Vestnik Saratovskogo gosagrouniversiteta im. N. I. Vavilova, 3, 31-34.

[9] Piskunov NS (1978), Differentsial'noe i integral'noe ischislenie dlya vuzov [Differential and integral calculations for higher schools] Moscow: Nauka.

[10] Il'in VA (1980), Sadovnichii, Matematicheskii analiz [Mathematical analysis]. Moscow: Nauka.

[11] Demin EE (2007), Improvement of technological processes and manure loading tools: Doctoral thesis. Saratov.

[12] Dubinin VF, Pavlov PI, Khitrova NV (2000), Shnekofrezernyi pitatel' pogruzchika organicheskikh udobrenii [Shredding screw loader of organic fertilizer]. Traktory i sel'skokhozyaistvennye mashiny, 10, 14-15.

[13] Pavlov PI, Khakimzyanov RR (2001), Pogruzchik organicheskikh udobrenii [Loader of organic fertilizers]. Sel'skii mekhanizator, 2, 48 . 